\title{
Richard Jones: Call of nature: the secret life of dung
}

\author{
Pelagic Publishing, 2017, 292 pp, £16.99 (Hardback), ISBN 978-1-78427-105-3
}

\author{
Darren J. Mann ${ }^{1}$
}

Published online: 30 June 2017

(C) Springer International Publishing Switzerland 2017

Not since Miss Felicity Beedles' World of Poo (Pratchett 2012) have I enjoyed reading a book so much. Written in a light hearted manner with ecological concepts interspersed with natural history and personal experiences, this book is both informative and engaging. The first few chapters take you on a journey through the human digestive system and beyond, but the bulk of the book is dedicated to the biology, behaviour, ecology and importance of the coprophilous community.

The ecological chapters are strongly biased towards the author's personal favourite the beetles and in particular the 'true' dung beetles (Coleoptera: Scarabaeoidea), with short appearances of other beetle groups (mostly predators) and flies. Sadly mites and in particular the phoretic species are largely ignored, although closely associated with their dung beetle transport and being valuable predators of fly eggs and larvae. This omission is reflective of current knowledge, since there has been little research on the majority of the coprophilous fauna and fauna.

From the Wombats' curiously cubic shaped pellets to the splatter of a heron, chapter eleven's illustrated guide should assist with the identification of frequently encountered dung. Though Eurocentric and covering a limited number species, a more comprehensive guide would certainly require several volumes in itself. Beyond the understandably limited scope my one, if small criticism of the guide is with cow pats. The description could be improved with the addition of native breeds on unimproved pasture, which unlike the semi-liquid flattened dollop of modern dairy and beef cattle on improved

Darren J. Mann

darren.mann@oum.ox.ac.uk

1 Head of Life Collections, Oxford University Museum of Natural History, Parks Road, Oxford OX1 3PW, UK pastures, has a very different consistency and a profile more akin to that of horse dung. Although this may seem trivial, this change in dung consistency has certainly had an adverse effect on dung beetles, as some species are unable to cope with the high water content of dung from intensively farmed cattle.

The chapter on 'Dung inhabitants and dung feeders' is well illustrated with black and white figures of many widespread inhabitants of dung. Since most people are only aware of African dung beetles rolling balls across the savannah (as seen on TV), this chapter may contain a few surprises, such as the moth specialising on sloth dung. The guide would have benefited from some colour images showing the rainbow of colours exhibited by some residents of this monochromatic habitat. Even in the UK with its depauperate dung fauna there are species with metallic green and purple undersides. The final chapter 'a scatological dictionary' is packed full of dung related words from the obsolete to the colloquial. There is a reasonable list of references, including most of the major works and recent research. The book has a good index including species names.

If you've ever wondered what goes on in a dung pile or consider dung beetles of little interest or importance, this book should remedy that. Filled with fun faecal facts and entertaining anecdotes this book deserves a place on everyone's bookshelf.

\section{Compliance with ethical standards}

Conflict of interest I can confirm that there is no conflict of interest.

\section{Reference}

Pratchett T (2012) Miss Felicity Beedle's ‘The world of poo'. Doubleday, London 